\section{Belém do Pará: uma metrópole amazônica à luz do olhar interdisciplinar}

\author{
Por Rubens da Silva Ferreira \\ Universidade Federal do Pará \\ (rubenspa@yahoo.com)
}

Lévi-Strauss (1989) - sobre a cidade que ostenta o título de 'Metrópole da Amazônia'. Enquanto tal, as pesquisas que aparecem sintetizadas em "Belém do Pará...", algumas das quais resultantes de trabalhos defendidos em cursos de pós-graduação, revelam um espaço complexo, no qual estão impressas particularidades históricas e simbólicas que ajudam o leitor a compreender a identidade dos belenenses. Numa outra dimensão, a complexidade na metrópole paraense é constituída por um mosaico psicossocial diverso. Por meio

SIMONIAN, Ligia Terezinha Lopes (Org.). Belém do Pará: história, cultura e sociedade. Belém: NAEA/UFPA/FAPESPA, 2010. 717 p. il. ISBN 978-85-7143-079-2.

Belém, capital do estado do Pará, foi tomada como mote para uma diversidade de estudos, sob abordagens distintas, apresentados no seminário "Belém do Pará: História, Cultura e Sociedade", promovido pelo Núcleo de Altos Estudos Amazônicos da Universidade Federal do Pará (NAEA/UFPA) entre os dias 28 e 30 de maio de 2003. Idealizado pela antropóloga Ph. D. Ligia T. L. Simonian, o evento resultou em 26 trabalhos, que inspiraram a ideia de publicar um livro em comemoração aos 388 anos da cidade, em 16 de janeiro do ano seguinte. Todavia, a dificuldade na captação dos recursos acabou por retardar o projeto. Passados oito anos da realização do seminário, dia 22 de junho de 2011, a Editora do NAEA/UFPA lançou a obra homônima, organizada por Ligia Simonian.

Visto sob um olhar contemporâneo, o livro "Belém do Pará..." reúne contribuições de 28 autores com formação em diferentes áreas do conhecimento, quer assinando trabalhos individuais ou em coautoria. Tem-se, então, antropólogos, arquitetos, historiadores, farmacêuticos, pedagogos, assistentes sociais, bibliotecários, geógrafos, filósofos, sociólogos e comunicólogos, entre outros que, em seu conjunto e dentro de suas respectivas especialidades acadêmicas, produzem uma bricolage - no sentido de dele, é possível evidenciar como gênero e expressões de comportamento individuais e/ou coletivos, por exemplo, sustentam a dinâmica da vida social em Belém. A economia local, sob o enfoque micro, bem como as políticas públicas para a cidade, também são tomadas no livro para refletir a cidade em seu nível de desenvolvimento. Nesse sentido, são destacados os modos de saber-fazer e os conhecimentos tradicionais que os sujeitos utilizam na geração de renda e também as estratégias políticas e técnicas da gestão municipal da época para Belém.

O prefácio do livro é assinado pelo Dr. Brasilmar Ferreira Nunes, professor titular do Departamento de Sociologia da Universidade de Brasília (UnB). Com o título "Belém: observação e experiência em uma metrópole brasileira", o prefaciador apresenta a cidade como uma obra que desconstrói o caráter exótico que os meios de comunicação produzem sobre ela. Assim, a leitura de cada capítulo revela não somente as peculiaridades locais, mas também as similares com as demais metrópoles brasileiras. Neste ponto, emergem, aqui e acolá, as conexões de Belém com a lógica de uma realidade global, na qual vida, cultura, política, economia e tradição são permanentemente tensionadas por forças externas que estão para além do poder do Estado. Ler o prefácio é um cuidado primeiro para não se perder no que Nunes se refere como um puzzle, que mistura muitos lugares, pessoas e fatos que dão sustentação e unidade aos capítulos escritos pelos autores reunidos em "Belém do Pará...".

A introdução é da autoria da organizadora do livro. Nessa parte, além de fornecer apontamentos sobre a 
história da cidade, Ligia Simonian procura urdir os três eixos temáticos em torno dos quais são construídas as leituras dos experts sobre a capital paraense. Ao critério da organizadora, a distribuição e o arranjo dos capítulos seguem exatamente aos eixos História, Cultura e Sociedade. Para Simonian, a obra é de natureza interdisciplinar, quer pelo enfoque quer pelas estratégias metodológicas utilizadas, nas quais sobressaem a pesquisa documental, a história oral e o trabalho de campo. Este último, aliás, por estar disseminado no contexto de várias disciplinas, pode ser percebido em muitos capítulos de "Belém do Pará..." como o preferido na produção de evidências junto aos atores sociais que nasceram ou migraram para essa cidade amazônica.

Na sequência à Introdução, tem-se o paper de autoria do geógrafo José Ademir de Oliveira. Em um recorte temporal que compreende o período 1920-1967, o autor analisa a paisagem regional sob a perspectiva da problemática das cidades amazônicas após o ciclo econômico bem sucedido de exploração da borracha. Utilizando as categorias de análise 'centro' e 'periferia', muito debatidas nas décadas de 1960 e 1970 (Shils, 1972) nos estudos macroeconômicos, Oliveira compreende que a paisagem urbana das cidades na Amazônia sofre os efeitos de movimentos políticos e econômicos efêmeros. Dessa maneira, continuidades e rupturas seguem alimentando a esperança por um desenvolvimento que parece nunca chegar à periferia. Embora o capítulo não trate especificamente de Belém, ele fornece as bases para que o leitor conheça o panorama histórico que tem contribuído para a precariedade da vida das populações que vivem nessa metrópole nos dias atuais.

Em relação aos estudos propriamente ditos sobre a capital paraense, o eixo História reúne nove capítulos. Fernando Luiz Tavares Marques apresenta os resultados das escavações arqueológicas na área do Projeto Feliz Lusitânia, a partir das quais têm sido identificados testemunhos pré-históricos. Ligia Simonian, por sua vez, debruça-se na pesquisa histórica sobre os indígenas que viviam onde hoje é Belém, a exemplo dos Tupinambá, bem como dos que foram trazidos forçadamente para a cidade para serem utilizados como força de trabalho escrava no empreendimento colonial. Magda Ricci estuda a cidade a partir da arte, precisamente por meio de duas telas do italiano Alfredo Norfini (1867-1944), que representam a visão do pintor sobre a Cabanagem. Aldrin Figueiredo constrói uma narrativa sobre a Guerra do Paraguai, combinando a memória histórica a uma partida de futebol pela Taça Libertadores da América, realizada em 2003, na cidade de Belém, em que competiam o time paraense chamado de Paysandu e o time paraguaio Cerro Porteño. Adriana Diogo interessa-se pela Vila da Barca, área conhecida na cidade pelas casas de palafita construídas sobre a baía de Guajará. De Marlene Schlup tem-se o paper sobre as praças e os coretos que existem em Belém do Pará, registrando a história, os usos sociais e apontando para a necessidade de ações de conservação permanente por parte do poder público. Luiz Leal assina o texto sobre a prática da capoeira e o folguedo de boibumbá, em torno dos quais foram construídos discursos depreciativos por seu caráter popular e por envolver grupos étnicos historicamente discriminados. Carmem Rodrigues faz uma etnografia do bairro do Jurunas, conhecido pela Escola de Samba Rancho "Não Posso me Amofiná" e pela manutenção de outros folguedos, cada vez menos comuns em Belém do Pará, e que por isso o caracterizam como um bairro festivo. O eixo História é fechado com o capítulo de autoria de Ângela Corrêa, que se volta para as manifestações culturais da cidade nas primeiras décadas do século $X X$, realizadas em espaços que funcionavam como marcadores entre a elite local e as classes mais populares.

A Cultura forma o segundo eixo de "Belém do Pará...", sob o qual estão agrupados nove capítulos. O primeiro é de autoria de Marcus Leite, em que o romance de Dalcídio Jurandir, intitulado "Belém do Grão Pará", é tomado como unidade de análise para entender como as personagens femininas se relacionam com a capital paraense. A literatura 
também é recorrida por Relivaldo Oliveira, que reflete sobre a cidade, com suas ruas, monumentos e pessoas, a partir do livro "Altar em Chamas", do escritor paraense João de Jesus Paes Loureiro. Lucilia Matos investiga a arte circense em suas possibilidades educativas e de lazer, com base na experiência do Projeto Escola Circo, desenvolvido pela Fundação Papa João XXIII, que atendia a crianças e adolescentes em situação de vulnerabilidade social e econômica. Os registros iconográficos sobre a Belém da belle époque são analisados por Luiz Costa, o que se dá com base no acervo do Museu de Arte de Belém e do Museu Paraense Emílio Goeldi, de forma que o primeiro reúne obras que produzem um olhar nativo da cidade e de suas riquezas, enquanto o segundo evidencia o olhar de naturalistas e de fotógrafos estrangeiros. Interessada pela atividade dos erveiros e das erveiras da feira do Ver-o-Peso, área de visitação turística na capital paraense, Estér Baptista investiga o cultivo, a comercialização e os usos das plantas medicinais. Sob o viés da sustentabilidade, Denise Cardoso estuda o cipó titica (Heteropsis sp. (Araceae)), muito utilizado na fabricação de móveis e utensílios artesanais em Belém. Marilena Silva dirige seu foco para o artesanato de miriti (Mauritia flexuosa Mart.), no município de Abaetetuba (PA), e para a cerâmica fabricada no distrito de Icoaraci, em Belém, apontando a necessidade da preservação e do uso sustentável desses insumos. O texto de Márcia Lasmar constrói-se em torno da produção e do uso do carvão vegetal na capital paraense, o que tem se dado de forma negativa diante do impacto da atividade sobre a floresta pela crescente utilização desse recurso no comércio informal de alimentos. Cristina Maués, Leila Kettle e Orenzio Soler escrevem sobre uma experiência na utilização dos conhecimentos tradicionais para a produção de medicamentos de menor preço, no contexto do programa municipal chamado "Farmácia Nativa", encerrado com fim do mandato do prefeito Edmilson Rodrigues, à época filiado ao Partido dos Trabalhadores (PT).

O eixo final, Sociedade, é composto por sete capítulos. Rubens Ferreira faz uma etnografia sobre o modo como as travestis fazem usos distintos da cidade, evidenciando como esse segmento se relaciona com a dinâmica do espaço urbano. O problema das gangues é trazido para discussão no capítulo escrito por Mário Xavier e Ligia Simonian, as quais constroem determinadas territorialidades para reivindicar um poder baseado no medo e na força física. Ana Lidia Pantoja também assina trabalho, em coautoria com Ligia Simonian, sobre o papel de mulheres afrodescendentes na manutenção da economia familiar intergeracional na feira do Ver-o-Peso, em que são presença dominante. Do ponto de vista da política local, tem-se o trabalho de Edmilson Rodrigues, prefeito de Belém entre 1997 e 2004, em que relata e analisa, entre outras coisas, a experiência da participação popular na gestão da cidade. A baía do Sol, na ilha de Mosqueiro, parte insular de Belém, é tomada como espaço empírico referencial na investigação de Ligia Simonian e José Bittencourt sobre a articulação do movimento social por políticas públicas socioambientais. Na perspectiva das políticas públicas, tem-se também o trabalho de Solange Gayoso, que descreve e analisa a experiência de construção do "Plano de Desenvolvimento Local Riacho", que previa, entre outras coisas, a construção de habitações e equipamentos urbanos, bem como melhorias sanitárias para os moradores dessa área de ocupação humana irregular. O último capítulo do livro é de autoria de Silvana Costa, que se detém no estudo sobre a paisagem, a arquitetura e o ecoturismo na ilha de Mosqueiro, com base na experiência do Hotel Fazenda Paraíso, concluindo que nesse empreendimento o lazer se sobrepõe à proposta de sustentabilidade, tal como revela, por exemplo, a ausência de controle de poluentes e de eliminação de lixo.

Ao final do livro, a organizadora oferece ao leitor o apêndice "Fontes documentais sobre a presença indígena em Belém do Pará", fruto da pesquisa documental realizada no Arquivo Público do Estado do Pará (APEP) para o quarto capítulo. De caráter complementar também é a consulta aos currículos resumidos dos autores e das autoras que fecham a obra. A preocupação com as informações e com 
os recursos adicionais que aparecem nos livros assinados pela organizadora, a exemplo de "Belém do Pará...", são reveladores não apenas de uma vocação científica, mas também do compromisso com as pesquisas futuras que essas publicações podem suscitar aos leitores. $\bigcirc$ mesmo cuidado é percebido no material ilustrativo, quase todo em cores, uma marca dos antropólogos na tradição do uso da imagem, que, desde Malinowski (1997[1967]), entendem a fotografia como recurso informativo que se associa à compreensão do dado etnográfico, ampliando-a.

Por fim, importa dizer que "Belém do Pará..." é uma obra que atualiza o olhar do leitor sobre a cidade que evoluiu de uma pequena fortificação militar para ganhar ares de metrópole, e que, em função dessas transformações históricas, culturais e sociais que se processam continuamente, tem passado um desafio duplo a enfrentar em direção ao desenvolvimento. Por um lado, há de preservar os registros materiais de sua formação espacial e humana, sobretudo para a realização de pesquisas como as que compõem o livro "Belém do Pará...". Por outro, as políticas públicas ainda precisam avançar muito no que se refere à melhoria das condições de vida da população que vive nessa cidade, quer em sua porção continental ou insular. Assim, a problemática urbana, social, ambiental, cultural e econômica, suscitada em maior ou menor grau nos capítulos escritos por autores de formação acadêmica diferenciada, convida pesquisadores, docentes e estudantes de cursos universitários a pensarem em novos olhares e perspectivas de análise para a cidade de Belém do Pará.

\section{REFERÊNCIAS}

LÉVI-STRAUSS, Claude. O pensamento selvagem. Campinas: Papirus, 1989.

MALINOWSKI, Bronislaw. Um diário no sentido estrito do termo. Rio de Janeiro: Record, 1997.

SHILS, Edward Albert. The constitution of society. Chicago: The University of Chicago Press, 1972. 